\title{
ANALISIS DISKRIMINAN BAURAN PEMASARAN TERHADAP PERSEPSI KONSUMEN UNTUK MEMUTUSKAN PEMBELIAN SEPEDA MOTOR MATIC MEREK HONDA DAN YAMAHA DI STIE DEWANTARA
}

\author{
${ }^{1)}$ Benny Osta Nababan, ${ }^{2)}$ Billy Permana \\ ${ }^{1)}$ Dosen Program Studi Manajemen, STIE Dewantara \\ Jl. Raya Pemda Bojong Depok Baru III, Karadenan, Cibinong, Bogor, Jawa Barat 16913,Indonesia \\ Email: benny.osta@dewantara.ac.id \\ ${ }^{2)}$ Alumni Program Studi Manajemen, STIE Dewantara \\ J1. Raya Pemda Bojong Depok Baru III, Karadenan, Cibinong, Bogor, Jawa Barat 16913,Indonesia \\ Email: billypermana17@gmail.com
}

\begin{abstract}
This research was conducted to determine differences in consumer perceptions of Honda and Yamaha brand motorcycles. Data were collected by survey technique to 100 students of STIE Dewantara who used automatic motorcycles from Honda and Yamaha in 2013 and above. The results obtained from this study: (1) the score on the test of the greater difference in average Honda motorcycles compared to Yamaha; (2) there are 4 differences in variables between groups, product variables, location and promotion making the reason for consumers to decide to buy a Honda motorcycle while for consumer price variables prefer to buy a Yamaha motorcycle; (3) There are differences in behavior between Honda and Yamaha motorcycle users because they have a sig <0.1 value in the Entered / Removed Variables table; (4) Dependent variable $(Y)$ can be explained by all independent variables (product, price, location and promotion) of $75.34 \%$, which means that all independent variables have a positive effect on the dependent variable $(Y)$ of purchasing decisions; (5) Honda motorcycles have a positive sign $(+)$ with independent variables (product, location and promotion) while Yamaha motorbikes have a negative sign (-) with independent variables (price); (6) The discriminant model is suitable to be used and is able to classify it properly for discriminant analysis in this study because it obtained a high accuracy rate of $96 \%$.
\end{abstract}

Keywords: Perception, Discriminant Analysis, Marketing Mix.

\begin{abstract}
ABSTRAK
Penelitian ini dilakukan untuk mengetahui perbedaan persepsi konsumen sepeda motor merek Honda dan Yamaha. Pengambilan data dilakukan dengan teknik survei kepada 100 mahasiswa mahasiswi STIE Dewantara yang menggunakan sepeda motor matic merk Honda dan Yamaha tahun 2013 ke atas. Hasil yang diperoleh dari penelitian ini: (1) nilai skor pada uji perbedaan rata-rata lebih besar sepeda motor Honda dibanding Yamaha; (2) terdapat 4 perbedaan variabel antar grup, variabel produk, lokasi dan promosi menjadikan alasan untuk konsumen dalam memutuskan membeli sepeda motor Honda sedangkan untuk varibel harga konsumen lebih memilih untuk membeli sepeda motor Yamaha; (3) Ada perbedaan perilaku antara pengguna sepeda motor Honda maupun Yamaha karena memiliki nilai sig $<0,1$ pada tabel Variables Entered/Removed; (4) Variabel terikat (Y) dapat dijelaskan oleh semua variabel bebas (produk, harga, lokasi dan promosi) sebesar 75,34\% artinya semua variabel bebas berpengaruh positif terhadap variabel terikat (Y) keputusan pembelian; (5) sepeda motor Honda memiliki tanda positif (+) dengan variabel bebas (produk, lokasi dan promosi) sedangkan sepeda motor Yamaha memiliki tanda negatif (-) dengan variabel bebas (harga); (6) Model diskriminan layak digunakan dan mampu melakukan klasifikasi dengan tepat untuk analisis diskriminan pada penelitian ini karena diperoleh angka ketepatan yang tinggi yaitu $96 \%$.
\end{abstract}

Kata kunci: Persepsi, Analisis Diskriminan, Bauran Pemasaran. 


\section{PENDAHULUAN}

\subsection{Latar Belakang}

Pada zaman yang sedang berkembang saat ini sepeda motor merupakan alat transportasi untuk kebutuhan sehari-hari bagi semua kalangan. Selain itu sepeda motor juga dipandang sebagai bagian dari gaya hidup (lifestyle) masyarakat. Dalam kondisi seperti ini, keputusan memilih merek turut berperan dalam gaya hidup modern, sehingga keinginan untuk membeli produk yang bermerek turut mewarnai pola konsumsi seseorang. Kondisi ini membawa peluang besar bagi perusahaan otomotif khususnya dibidang sepeda motor.

Masing-masing perusahaan sepeda motor mempunyai strategi tersendiri dalam upaya menarik konsumen agar tetap mempertahankan eksistensi perusahaan tersebut mulai dari strategi harga, promosi, bahkan kualitas produk yang bagus. Berikut ini data penjualan sepeda motor Tahun 2017 :

Tabel 1. Data Penjualan Sepeda Motor Tahun 2017

\begin{tabular}{|l|r|r|r|r|r|r|}
\hline \multicolumn{1}{|c|}{ Bulan } & \multicolumn{1}{c|}{ Honda } & Yamaha & \multicolumn{1}{c|}{ Suzuki } & Kawasaki & \multicolumn{1}{c|}{ TVS } & \multicolumn{1}{c|}{ Total } \\
\hline Januari & 368.739 & 94.117 & 3.511 & 7.370 & 142 & 473.879 \\
\hline Februari & 345.921 & 93.511 & 5.904 & 8.298 & 129 & 453.763 \\
\hline Maret & 358.524 & 98.040 & 8.600 & 8.601 & 131 & 473.896 \\
\hline April & 274.155 & 101.908 & 5.879 & 6.002 & 101 & 388.045 \\
\hline Mei & 394.751 & 122.186 & 8.526 & 5.915 & 118 & 531.496 \\
\hline Juni & 263.854 & 105.133 & 6.270 & 4.143 & 67 & 379.467 \\
\hline Juli & 403.487 & 120.608 & 7.312 & 6.690 & 79 & 538.176 \\
\hline Agustus & 418.931 & 123.620 & 6.279 & 6.009 & 84 & 554.923 \\
\hline September & 408.116 & 124.360 & 6.823 & 7.224 & 84 & 546.607 \\
\hline Oktober & 436.974 & 129.636 & 6.172 & 6.658 & 112 & 579.552 \\
\hline November & 430.487 & 109.834 & 3.617 & 6.274 & 91 & 550.303 \\
\hline Desember & 281.949 & 125.258 & 3.298 & 5.453 & 38 & 415.996 \\
\hline Total & 4.385 .888 & 1.348 .211 & 72.191 & 78.637 & 1.176 & $\mathbf{5 . 8 8 6 . 1 0 3}$ \\
\hline \% & $\mathbf{7 4 , 5 1 \%}$ & $22,90 \%$ & $1,23 \%$ & $1,34 \%$ & $0,02 \%$ & $100 \%$ \\
\hline
\end{tabular}

Sumber: www.aisi.or.id tahun 2018

Jika dilihat dari di atas penjualan sepeda motor merek Honda menempati urutan pertama, sedangkan diurutan kedua yaitu sepeda motor merek Yamaha dan urutan selanjutnya oleh merek lain. Oleh karena itu peneliti ingin membandingkan bagaimana persepsi konsumen mengenai sepeda motor merek Honda dan Yamaha.

\subsection{Batasan Masalah}

Agar permasalahan yang diteliti lebih terfokus dan sesuai dengan tujuannya serta dikarenakan keterbatasan waktu dan pemahaman kajian teori maka penelitian dibatasi yaitu Mahasiswa STIE Dewantara yang menggunakan sepeda motor merek Honda atau Yamaha berjenis matic dan diproduksi tahun 2013 ke atas yang sampai saat ini masih diproduksi sebagai responden.

\subsection{Rumusan Masalah}

Berdasarkan latar belakang tersebut, maka perumusan masalah penelitian ini adalah sebagai berikut:

1. Bagaimana membedakan variabel bebas (produk, harga, lokasi dan promosi) pengguna sepeda motor Honda dan pengguna sepeda motor Yamaha di STIE Dewantara?

2. Bagaimana menentukan variabel bebas (produk, harga, lokasi dan promosi) dari perbedaan antar grup (sepeda motor Honda dan sepeda motor Yamaha)?

3. Bagaimana mengetahui perilaku pengguna sepeda motor (sepeda motor Honda dan sepeda motor Yamaha)?

4. Bagaimana menentukan seberapa besar variabel terikat (sepeda motor) dan dapat dijelaskan oleh variabel bebasnya (produk, harga, lokasi dan promosi) oleh model diskriminannya?

5. Bagaimana menentukan variabel bebas (produk, harga, lokasi dan promosi) yang masuk grup sepeda motor Honda dan sepeda motor Yamaha sehingga bersikap positif terhadap atribut variabel bebas?

6. Bagaimana menentukan apakah model diskriminan tersebut mampu melakukan klasifikasi atau prediksi 
responden dengan tepat untuk analisis diskriminan?

\subsection{Tujuan Penelitian}

Tujuan penelitian ini adalah sebagai berikut:

1. Untuk membedakan variabel bebas (produk, harga, lokasi dan promosi) pengguna sepeda motor Honda dan konsumen sepeda motor Yamaha di STIE Dewantara.

2. Untuk menentukan variabel bebas (produk, harga, lokasi dan promosi) dari perbedaan antar grup (sepeda motor Honda dan sepeda motor Yamaha).

3. Untuk mengetahui perilaku pengguna sepeda motor (sepeda motor Honda dan sepeda motor Yamaha).

4. Untuk menentukan seberapa besar variabel terikat (sepeda motor) dan dapat dijelaskan oleh variabel bebasnya (produk, harga, lokasi dan promosi) oleh model diskriminannya

5. Untuk menentukan variabel bebas (produk, harga, lokasi dan promosi) yang masuk grup sepeda motor Honda dan sepeda motor Yamaha sehingga bersikap positif terhadap atribut variabel bebas.

6. Untuk menentukan apakah model diskriminan tersebut mampu melakukan klasifikasi atau prediksi responden dengan tepat untuk analisis diskriminan.

\section{TINJAUAN PUSTAKA}

\subsection{Landasan Teori}

\subsubsection{Bauran Pemasaran}

Bauran pemasaran merupakan hal yang penting dalam pemasaran yang menentukan keberhasilan perusahaan dalam mengejar keuntungan. Kotler dan Keller (2012:101) menyatakan bahwa bauran pemasaran atau marketing mix adalah seperangkat alat yang digunakan perusahaan untuk terus menerus mencapai tujuan pemasarannya di pasar sasaran

Dalam bauran pemasaran terdiri dari empat variabel yang biasa disebut 4P yaitu produk (product), harga (price), lokasi (place) dan promosi (promotion).

a. Produk

Produk merupakan unsur pertama dan yang paling penting dalam bauran pemasaran. Kotler (2000:448) menjelaskan bahwa produk adalah segala sesuatu yang dapat ditawarkan ke pasar untuk diperhatikan, diperloleh, digunakan, atau dipasarkan meliputi barang-barang fisik, pengalaman, peristiwa, orang , tempat, properti, organisasi, gagasan.

Tjiptono (2008:65) telah mengungkapkan adanya delapan dimensi kualitas produk yang bisa dimainkan oleh pemasar yaitu, quality, durability, conformance to spesification, features, reability, aesthetics, percaived quality dan servicibility.

b. Harga

Harga merupakan satu-satunya unsur bauran pemasaran yang memberikan pemasukan atau pendapatan bagi perusahaan (Ghanimata, 2012:17). Harga dapat menunjukkan kualitas merek dari suatu produk, dimana konsumen mempunyai anggapan bahwa harga yang mahal biasanya mempunyai kualitas yang baik.

\section{c. Lokasi}

Lokasi merupakan salah satu faktor yang berpengaruh pada keputusan pembelian, dalam marketing mix atau bauran pemasaran lokasi dapat juga disebut dengan saluran distribusi perusahaan. Alma (2003:103) mengemukakan bahwa Lokasi adalah tempat perusahaan beroperasi atau tempat perusahaan melakukan kegiatan 
untuk menghasilkan barang dan jasa yang mementingkan segi ekonominya.

Menurut Mischitelli pemilihan tempat/lokasi fisik memerlukan pertimbangan cermat terhadap faktor-faktor berikut:
a. Place
b. Parking
c. Accesibility
d. Visibility
e. Infrastructure
d. Promosi

Promosi merupakan teknik komunikasi yang secara peng-gunaannya atau penyampaiannya dengan menggunakan media seperti: pers, televisi, radio, papan nama, poster dan lain-lain, yang tujuannya untuk menarik minat konsumen terhadap hasil produksi suatu perusahaan. Kotler dan Keller (2009:510) menyatakan bahwa promosi adalah berbagai cara untuk menginformasikan, membujuk dan mengingatkan konsumen secara langsung maupun tidak langsung tentang suatu produk atau brand yang dijual.

\subsubsection{Keputusan Pembelian}

Menurut Kotler (2002:184) keputusan pembelian adalah tindakan dari konsumen untuk mau membeli atau tidak terhadap produk dari berbagai faktor yang mempengaruhi konsumen dalam melakukan pembelian suatu produk atau jasa, biasanya konsumen selalu mempertimbangkan kualitas, harga dan produk sudah yang sudah dikenal oleh masyarakat sebelum konsumen memutuskan untuk membeli.

\subsubsection{Hubungan antara Persepsi dengan Keputusan Pembelian}

Persepsi konsumen terhadap suatu produk akan menjadi pertimbangan konsumen dalam menentukan pilihan produk mana yang akan dibeli. Jika persepsi tersebut tinggi maka konsumen akan tertarik dan mengevaluasi masukan- masukan informasi yang mereka dapat mengenai barang tersebut untuk kemudian membelinya. Untuk menghasilkan persepsi yang tepat bagi konsumen, perusahaan hendaknya memperhatikan kriteria evaluasi kualitas produk atau jasa yang ditawarkan dengan cara terus menerus, karena orang akan melupakan banyak hal yang mereka pelajari namun cenderung akan mengingat informasi yang mendukung pandangan dan keyakinan konsumen untuk membeli produk tesebut Kotler (2002:184).

\subsection{Definisi Operasional}

Definisi operasional adalah aspek penelitian yang memberikan informasi peneliti tentang bagaimana caranya mengukur variabel.

\section{Tabel 2. Definisi Operasional}

\begin{tabular}{|c|c|c|c|}
\hline Variabel & $\begin{array}{l}\text { Landasan } \\
\text { Teori }\end{array}$ & Indikator & $\begin{array}{c}\text { Skala } \\
\text { Pengukuran }\end{array}$ \\
\hline \multirow[t]{4}{*}{ Produk } & \multirow{4}{*}{$\begin{array}{l}\text { Tjiptono } \\
\text { (2008:65) }\end{array}$} & Keiritan bahan bakar & \multirow{18}{*}{$\begin{array}{c}\text { Skala Likert } \\
(1.5)\end{array}$} \\
\hline & & $\begin{array}{l}\text { Produk tidak mudah rusak dan memiliki umur } \\
\text { ekonomis yang lama }\end{array}$ & \\
\hline & & Daya tahan mesin yang tangguh & \\
\hline & & Penampilan produk yang menarik & \\
\hline \multirow[t]{3}{*}{ Harga } & \multirow{3}{*}{$\begin{array}{l}\text { Dinawan } \\
(2010: 36)\end{array}$} & Perbandingan harga dengan produk lain & \\
\hline & & Kesesuaian harga dengan kualitas produk & \\
\hline & & Keterjangkauan harga & \\
\hline \multirow[t]{4}{*}{ Lokasi } & \multirow{4}{*}{$\begin{array}{l}\text { Mischitelli } \\
(2000: 2)\end{array}$} & Lokasi penjualan yang strategis & \\
\hline & & Area parkir yang luas dan nyaman & \\
\hline & & Jangkauan akses menuju lokasi & \\
\hline & & \begin{tabular}{|l|} 
Jarak pandang lokasi \\
\end{tabular} & \\
\hline \multirow[t]{3}{*}{ Promosi } & \multirow{3}{*}{$\begin{array}{c}\text { Kotler (1996) } \\
\text { dalam Rosvita } \\
(2010: 28)\end{array}$} & Jangkauan promosi & \\
\hline & & Kuantitas penayangan iklan di media promosi & \\
\hline & & $\begin{array}{l}\text { Kualitas penyampaian pesan dalam } \\
\text { penayangan iklan di media promosi }\end{array}$ & \\
\hline \multirow{4}{*}{$\begin{array}{l}\text { Keputusan } \\
\text { Pembelian }\end{array}$} & \multirow{4}{*}{$\begin{array}{c}\text { Kotler } \\
(2004: 204)\end{array}$} & Pencarian informasi & \\
\hline & & Penilaian alternatif & \\
\hline & & Keputusan pembelian & \\
\hline & & Perilaku setelah membeli & \\
\hline
\end{tabular}

Sumber: hasil penelitian (2018)

\subsection{Kerangka Pemikiran}

Berdasarkan dari tinjauan pustaka dan penelitian terdahulu, maka dapat telah dibentuk kerangka pemikiran penelitian ini adalah : 


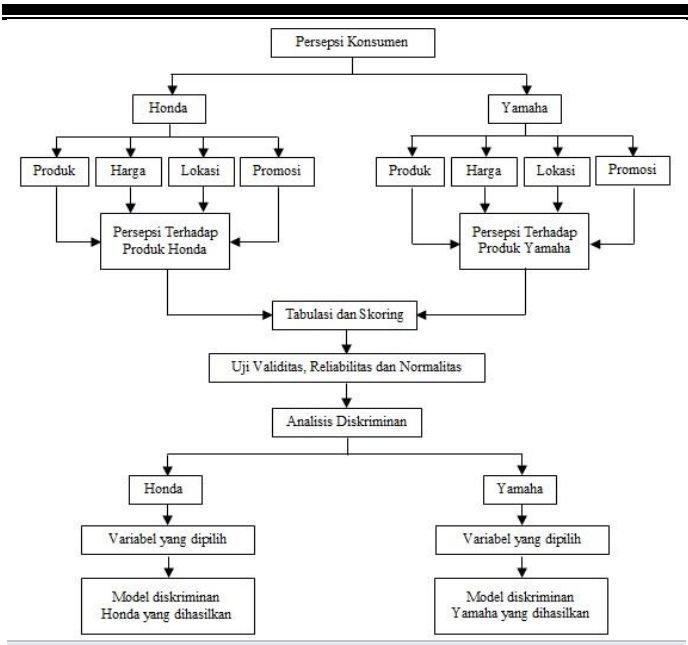

Gambar 1. Kerangka Pemikiran

Sumber: hasil penelitian (2018)

\section{METODE PENELITIAN}

\subsection{Jenis Penelitian}

Penelitian ini merupakan penelitian kuantitatif dengan desain komparatif. Penelitian komparatif menurut Sugiyono (2014:54) adalah penelitian yang membandingkan keadaan satu variabel atau lebih pada dua atau lebih sampel yang berbeda, atau dua waktu yang berbeda.

\subsection{Variabel Penelitian}

Arikunto (1998:99) variabel penelitian adalah objek penelitian atau apa yang menjadi perhatian suatu titik perhatian suatu penelitian.

1. Variabel Independen atau Bebas

Yang termasuk variabel independen atau bebas dalam penelitian ini adalah:
a. Produk $\left(\mathrm{X}_{1}\right)$
b. Harga $\left(\mathrm{X}_{2}\right)$
c. Lokasi $\left(\mathrm{X}_{3}\right)$
d. Promosi $\left(\mathrm{X}_{4}\right)$

2. Variabel Dependen atau Variabel Terikat

Yang termasuk variabel dependen atau terikat dalam penelitian ini adalah keputusan pembelian $(\mathrm{Y})$

\subsection{Lokasi dan Waktu}

Penelitian ini dilaksanakan di di STIE Dewantara yang beralamat di Jalan Raya Pemda Bojong Depok Baru III Karadenan, Cibinong Kab. Bogor. Waktu penelitian dilakukan mulai pada bulan Maret 2018 sampai dengan bulan Oktober 2018.

\subsection{Populasi dan Sampel}

Populasinya adalah mahasiswa/i STIE Dewantara yang memiliki dan menggunakan sepeda motor jenis matic merek Honda dan merek Yamaha produksi tahun 2013 ke atas yang sampai saat ini masih diproduksi sebagai responden, sedangkan untuk pengambilan sampelnya adalah 100 responden.

\subsection{Teknik Analisis Data}

Teknik analisis data dalam penelitian ini menggunakan tabulasi dan proses skoring, uji validitas, uji reliabilitas,uji normalitas dan uji hipotesis dengan analisis diskriminan.

\section{HASIL DAN PEMBAHSAN}

\subsection{Uji Beda Rata-rata Seluruh} Variabel

Tabel 3. Hasil Uji Beda Rata-rata Seluruh Variabel

\begin{tabular}{clcl}
\hline \multirow{2}{*}{ No } & Variabel & $\begin{array}{r}\text { Sepeda } \\
\text { Motor } \\
\text { Honda }\end{array}$ & $\begin{array}{l}\text { Sepeda } \\
\text { Motor } \\
\text { Yamaha }\end{array}$ \\
\cline { 3 - 4 } & & 223,75 & 192,25 \\
\hline 1 & Produk & 183,33 & 223,00 \\
\hline 2 & Harga & 217,50 & 194,75 \\
\hline 3 & Lokasi & 215,33 & 189,33 \\
\hline 5 & Promosi & 218,00 & 212,75 \\
\hline & Keputusan & Pembelian & \\
\hline Total Rata-rata & $\mathbf{2 1 1 , 5 8}$ & $\mathbf{2 0 2 , 4 2}$
\end{tabular}

Sumber: Data primer yang diolah, 2018.

Dapat dilihat skor pada variabel produk sepeda motor Honda lebih besar dibandingkan dengan sepeda motor Yamaha, artinya konsumen lebih tertarik 
dengan produk Honda. Selanjutnya skor pada variabel harga sepeda motor Yamaha lebih besar dibandingkan dengan sepeda motor Honda, artinya konsumen lebih memilih sepeda motor Yamaha karena melihat variabel harga. Lalu skor pada variabel lokasi sepeda motor Honda lebih besar dibandingkan dengan sepeda motor Yamaha, artinya konsumen lebih tertarik membeli sepeda motor Honda karena lokasi penjualan dan bengkel resminya yang strategis mudah ditemukan. Selanjutnya skor pada variabel promosi sepeda motor Honda lebih besar dibandingkan dengan sepeda motor Yamaha, artinya konsumen lebih tertarik membeli sepeda motor Honda karena promosi yang dilakukan oleh Honda. Selanjutnya hasil skor pada variabel keputusan pembelian sepeda motor Honda lebih tinggi dibandingkan sepeda motor Yamaha.

Berdasarkan hasil dari perbedaan total rata-rata seluruh variabel menunjukkan skor konsumen terhadap sepeda motor Honda lebih tinggi sebesar 211,58 poin, sedangkan skor konsumen terhadap sepeda motor Yamaha sebesar 202,42 poin.

\subsection{Uji Validitas}

Uji Validitas digunakan untuk mengukur sah (valid) atau tidaknya suatu kuesioner.

\section{Tabel 4. Hasil Uji Validitas}

\begin{tabular}{cccc}
\hline Kriteria & r hitung & r tabel & Keterangan \\
\hline Produk & & & \\
\hline P1 & 0,770 & 0,1654 & Valid \\
\hline P2 & 0,447 & 0,1654 & Valid \\
\hline P3 & 0,667 & 0,1654 & Valid \\
\hline P4 & 0,555 & 0,1654 & Valid \\
\hline Harga & & & \\
\hline P1 & 0,825 & 0,1654 & Valid \\
\hline P2 & 0,492 & 0,1654 & Valid \\
\hline P3 & 0,822 & 0,1654 & Valid \\
\hline Lokasi & & & \\
\hline P1 & 0,742 & 0,1654 & Valid \\
\hline P2 & 0,601 & 0,1654 & Valid \\
\hline P3 & 0,515 & 0,1654 & Valid \\
\hline P4 & 0,750 & 0,1654 & Valid \\
\hline
\end{tabular}

\begin{tabular}{|c|c|c|c|}
\hline Promosi & & & \\
\hline P1 & 0,705 & 0,1654 & Valid \\
\hline $\mathrm{P} 2$ & 0,738 & 0,1654 & Valid \\
\hline P3 & 0,594 & 0,1654 & Valid \\
\hline \multicolumn{4}{|c|}{ Keputusan Pembelian } \\
\hline $\mathrm{P} 1$ & 0,716 & 0,1654 & Valid \\
\hline $\mathrm{P} 2$ & 0,476 & 0,1654 & Valid \\
\hline P3 & 0,594 & 0,1654 & Valid \\
\hline P4 & 0,637 & 0,1654 & Valid \\
\hline
\end{tabular}

Sumber: Data primer yang diolah, 2018.

Berdasarkan hasil pengujian pada table 4 dapat diketahui bahwa seluruh nilai $r$ hitung dari semua indikator memiliki hasil lebih besar dari pada $r$ tabel, maka dari itu dapat disimpulkan bahwa semua pertanyaan pada kuesioner dalam penelitian ini adalah valid.

\subsection{Uji Reliabilitas}

Reliabilitas atau keandalan adalah konsistensi dari serangkaian pengukuran atau serangkaian alat ukur. Dalam penelitian ini uji reliabilitas dilakukan dengan metode Alpha Cronbach diukur berdasarkan skala Cronbach 0 sampai 1 .

Tabel 5. Hasil Uji Reliabilitas

\begin{tabular}{lcc}
\hline Variabel & $\begin{array}{c}\text { Nilai } \\
\text { Cronbach's } \\
\text { Alpha }\end{array}$ & Keterangan \\
\hline Produk & 0,436 & Cukup Reliabel \\
\hline Harga & 0,542 & Cukup Reliabel \\
\hline Lokasi & 0,560 & Cukup Reliabel \\
\hline Promosi & 0,420 & Cukup Reliabel \\
\hline $\begin{array}{l}\text { Keputusan } \\
\text { Pembelian }\end{array}$ & 0,441 & Cukup Reliabel \\
\hline Sumber: Data primer yang diolah, 2018.
\end{tabular}

Berdasarkan Tabel 5. Hasil Uji Reabilitas diperoleh nilai Cronbach Alpha lebih besar dari 0,41, dengan demikian seluruh instrumen yang diuji dalam penelitian ini untuk variabel produk, harga, lokasi, promosi dan keputusan pembelian dapat dinyatakan cukup reliabel atau cukup baik. 


\subsection{Uji Normalitas}

Uji normalitas bertujuan untuk menguji apakah variabel bebas dan variabel terikat berdistribusi normal atau tidak. Suatu model dikatakan memenuhi asumsi normalitas apabila data menyebar disekitar garis diagonal dan mengikuti arah diagonal, sebaliknya jika data menyebar jauh dari garis diagonal dan tidak mengikuti arah diagonal maka model tidak memenuhi asumsi normalitas. Berikut adalah grafik hasil uji normalitas yang dilakukan dalam penelitian ini:

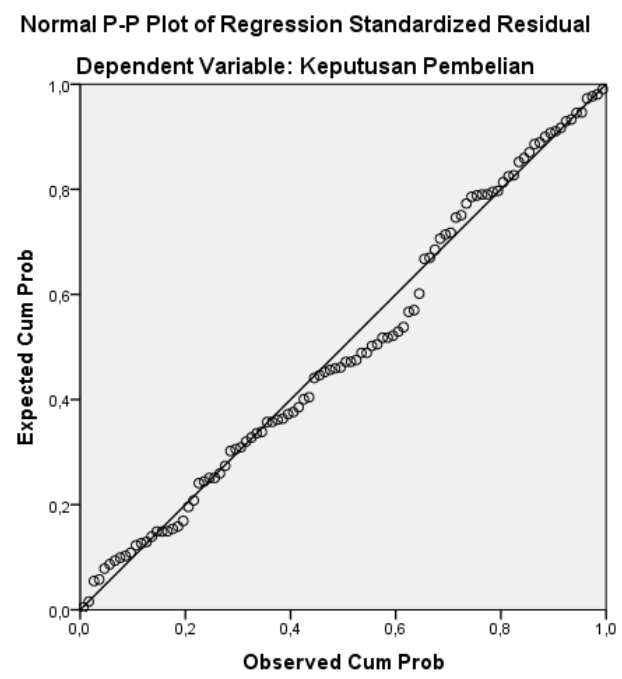

Gambar 2. Grafik Hasil Uji Normalitas

Sumber: Data Primer yang diolah, 2018.

Pada gambar merupakan grafik Non Probability Plot menunjukan titik-titik yang menyebar mengikuti arah garis diagonal, maka dari itu dapat disimpulkan bahwa model memenuhi asumsi normalitas atau layak untuk digunakan.

\subsection{Analisis Diskriminan}

\subsubsection{Analysis Case Processing Summary}

Bertujuan untuk membandingkan variabel independen (bebas) dari masingmasing kelompok pengguna sepeda motor merek Honda dan kelompok pengguna sepeda motor merek Yamaha.
Tabel 6. Hasil Uji Analysis Case

Processing Summary

\begin{tabular}{|ll|r|r|}
\hline Unweighted Cases & \multicolumn{1}{|c|}{ N } & Percent \\
\hline Valid & $\begin{array}{l}\text { Missing or } \\
\text { out-of-range } \\
\text { group codes } \\
\text { At least one } \\
\text { missing } \\
\text { discriminating } \\
\text { variable }\end{array}$ & 0 & 100 \\
& $\begin{array}{l}\text { Both missing } \\
\text { or out-of- } \\
\text { range group } \\
\text { codes and at } \\
\text { least one } \\
\text { missing } \\
\text { discriminating } \\
\text { variable }\end{array}$ & 0 & 0 \\
& & 0 & \\
Total & 0 & 0 \\
Excluded & & \\
Total & & 100 & 100 \\
\hline
\end{tabular}

Sumber: Data Primer yang diolah, 2018.

Tabel 6 menunjukkan tidak ada data yang hilang karena jumlah total $\mathrm{N}$ tidak ada yang berubah dengan jumlah data valid.

\subsubsection{Group Statistics}

Bertujuan untuk membandingkan variabel independen (bebas) dari masingmasing kelompok pengguna sepeda motor merek Honda dan kelompok pengguna sepeda motor merek Yamaha.

Tabel 7. Hasil Uji Group Statistics

\begin{tabular}{|c|c|c|c|c|c|}
\hline \multirow{2}{*}{\multicolumn{2}{|c|}{ SepedaMotor }} & \multirow{2}{*}{ Mean } & \multirow{2}{*}{$\begin{array}{c}\text { Std. } \\
\text { Deviation }\end{array}$} & \multicolumn{2}{|c|}{ Valid N (listwise) } \\
\hline & & & & Unweighted & Weighted \\
\hline \multirow{4}{*}{ Honda } & Produk & 17,90 & 1,329 & 50 & 50,000 \\
\hline & Harga & 11,02 &, 937 & 50 & 50,000 \\
\hline & Lokasi & 17,40 & 1,385 & 50 & 50,000 \\
\hline & Promosi & 12,92 & 1,007 & 50 & 50,000 \\
\hline \multirow{4}{*}{ Yamaha } & Produk & 15,38 &, 987 & 50 & 50,000 \\
\hline & Harga & 13,38 & 1,028 & 50 & 50,000 \\
\hline & Lokasi & 15,58 & 1,144 & 50 & 50,000 \\
\hline & Promosi & 11,36 & 921 & 50 & 50,000 \\
\hline \multirow{4}{*}{ Total } & Produk & 16,64 & 1,720 & 100 & 100,000 \\
\hline & Harga & 12,20 & 1,537 & 100 & 100,000 \\
\hline & Lokasi & 16,49 & 1,560 & 100 & 100,000 \\
\hline & Promosi & 12,14 & 1,239 & 100 & 100,000 \\
\hline
\end{tabular}

Sumber: Data Primer yang diolah, 2018. 
Jika dilihat dari nilai mean pada table diatas, konsumen lebih memilih sepeda motor Honda karena variabel produk, lokasi dan promosi, sedangkan konsumen yang memilih sepeda motor Yamaha karena variabel harga.

\subsubsection{Test of Equality of Group Means}

Bertujuan untuk menguji apakah ada perbedaan yang signifikan antara kelompok pengguna sepeda motor merek Honda dan sepeda motor merek Yamaha dari setiap variabel bebas yang ada.

Tabel 8. Hasil Uji Test of Equality of Group Means

\begin{tabular}{|l|r|r|r|r|r|}
\hline & $\begin{array}{r}\text { Wilks' } \\
\text { Lambda }\end{array}$ & F & df1 & df2 & Sig. \\
\hline Produk &, 458 & 115,87 & 1 & 98 &, 000 \\
Harga &, 405 & 144 & 1 & 98 &, 000 \\
Lokasi &, 656 & 51,305 & 1 & 98 &, 000 \\
Promosi &, 600 & 65,376 & 1 & 98 &, 000 \\
\hline
\end{tabular}

Sumber: Data Primer yang diolah, 2018.

Pada tabel 8 variabel Produk, Harga, Lokasi dan Promosi menunjukkan Sig $0,000(<0,1)$ yang berarti ada perbedaan setiap antar grup Honda maupun Yamaha.

Dengan signifikansi:

Sig $>0,1$ Tidak ada perbedaan antar grup Sig $<0,1$ Ada perbedaan antar grup

\subsubsection{Variables Entered/Removed}

Bertujuan untuk mengetahui variabel yang dihilangkan dan mengetahui variabel yang dapat dimasukkan dalam model diskriminan serta mengetahui apakah ada perbedaan perilaku konsumen.
Tabel 9. Hasil Uji Variables

Entered/Removed

\begin{tabular}{|c|c|c|c|c|c|c|c|}
\hline \multirow[t]{3}{*}{ Step } & \multirow[t]{3}{*}{ Entered } & \multicolumn{6}{|c|}{ Min. D Squared } \\
\hline & & \multirow[t]{2}{*}{ Statistic } & \multirow{2}{*}{$\begin{array}{l}\text { Between } \\
\text { Groups }\end{array}$} & \multicolumn{4}{|c|}{ Exact $F$} \\
\hline & & & & Statistic & df1 & df2 & Sig. \\
\hline 1 & Harga & 5,760 & $\begin{array}{l}\text { Honda } \\
\text { and } \\
\text { Yomaha }\end{array}$ & 144,001 & 1 & 98,000 & $6,00 \mathrm{E}-21$ \\
\hline 2 & Produk & 9,701 & $\begin{array}{l}\text { Honda } \\
\text { and } \\
\text { Yamaha }\end{array}$ & 120,026 & 2 & 97,000 & $5,82 \mathrm{E}-27$ \\
\hline 3 & Lokasi & 11,365 & $\begin{array}{l}\text { Honda } \\
\text { and } \\
\text { Yamaha }\end{array}$ & 92,772 & 3 & 96,000 & $2,93 \mathrm{E}-28$ \\
\hline 4 & Promosi & 12,009 & $\begin{array}{l}\text { Honda } \\
\text { and } \\
\text { Yamaha }\end{array}$ & 72,759 & 4 & 95,000 & $4,40 \mathrm{E}-28$ \\
\hline
\end{tabular}

At each step, the variable that maximizes the Mahalanobis distance between the two closest groups is entered.

a. Maximum number of steps is 8 .

b. Maximum significance of $\mathrm{F}$ to enter is .1.

c. Minimum significance of $\mathrm{F}$ to remove is .15 .

d. F level, tolerance, or VIN insufficient for further computation.

Sumber: Data Primer yang diolah, 2018.

Hasil menunjukkan tidak ada variabel yang dihilangkan dalam analisis, namun hasil menunjukkan bahwa semua variabel mempunyai nilai sig. $<0,1$ yang berarti ada perbedaan perilaku antara pengguna sepeda motor merek Honda maupun Yamaha.

\subsubsection{Eigenvalues}

Bertujuan untuk mengetahui variabel yang dihilangkan dan mengetahui variabel yang dapat dimasukkan dalam model diskriminan serta mengetahui apakah ada perbedaan perilaku konsumen.

Tabel 10. Hasil Uji Eigenvalues

\begin{tabular}{|l|r|r|r|r|}
\hline Function & Eigenvalue & $\begin{array}{c}\% \text { of } \\
\text { Variance }\end{array}$ & $\begin{array}{c}\text { Cumulative } \\
\%\end{array}$ & $\begin{array}{c}\text { Canonical } \\
\text { Correlation }\end{array}$ \\
\hline 1 & $3,064^{\circ}$ & 100,0 & 100,0 &, 868 \\
\hline
\end{tabular}

a. First 1 canonical discriminant functions were used in the analysis.

Sumber: Data Primer yang diolah, 2018.

Lihat Canonical Correlation pada tabel diatas 0,868 dikuadratkan menjadi $0,7534=75,34 \%$. Variabel terikat $(\mathrm{Y})$ dapat dijelaskan oleh semua variabel bebas (produk, harga, lokasi dan promosi) sebesar $75,34 \%$ artinya semua variabel bebas 
berpengaruh positif terhadap variabel terikat $(\mathrm{Y})$ keputusan pembelian.

\subsubsection{Wilks' Lambda}

Bertujuan untuk mengetahui ada atau tidak perbedaan yang signfikan diantara kelompok pengguna sepeda motor merek Honda dan pengguna sepeda motor merek Yamaha.

Tabel 11. Hasil Uji Wilks' Lambda

\begin{tabular}{|l|r|c|c|c|}
\hline $\begin{array}{c}\text { Test of } \\
\text { Function(s) }\end{array}$ & $\begin{array}{c}\text { Wilks' } \\
\text { Lambda }\end{array}$ & $\begin{array}{c}\text { Chi- } \\
\text { square }\end{array}$ & df & Sig. \\
\hline 1 &, 246 & 134,598 & 4 &, 000 \\
\hline
\end{tabular}

Sumber: Data Primer yang diolah, 2018.

Pada tabel diatas menunjukan nilai signifikansi $0,000(<0,1)$. Yang artinya terdapat perbedaan yang signifikan antara kedua kelompok (pengguna sepeda motor merek Honda dan pengguna sepeda motor merek Yamaha dalam model diskriminan.

\subsubsection{Structure Matrix dan Functions at Group Centroids}

Bertujuan untuk mengetahui variabel Independen (Produk, Harga, Lokasi dan Promosi) yang membedakan. Dari paling yang besar membedakan dengan tanda positif dan paling kecil membedakan dengan tanda negatif.

Tabel 12. Hasil Uji Structure Matrix

\begin{tabular}{|l|r|}
\hline \multirow{2}{*}{} & \multicolumn{2}{|c|}{ Function } \\
\cline { 2 - 2 } & \multicolumn{2}{|c|}{1} \\
\hline Harga &,- 693 \\
Produk &, 621 \\
Promosi &, 467 \\
Lokasi &, 413 \\
\hline
\end{tabular}

Pooled within-groups correlations between discriminating variables and standardized canonical discriminant functions

Variables ordered by absolute size of correlation within function.

Sumber: Data Primer yang diolah, 2018.
Tabel 13. Hasil Uji Functions at Group Centroids

\begin{tabular}{|c|c|}
\hline \multirow[b]{2}{*}{ Sepeda Motor } & Function \\
\hline & 1 \\
\hline Honda & 1,733 \\
\hline Yamaha & $-1,733$ \\
\hline
\end{tabular}

Sumber: Data Primer yang diolah, 2018.

Pada tabel 12 dan 13 konsumen pengguna sepeda motor merek Honda memiliki tanda positif (+), sedangkan konsumen pengguna sepeda motor merek Yamaha memiliki tanda negatif (-). Dapat disimpulkan bahwa variabel bebas yang termasuk konsumen pengguna sepeda motor merek Honda adalah (Produk, Lokasi dan Promosi) karena memiliki tanda positif (+). Untuk variabel bebas yang termasuk konsumen pengguna sepeda motor merek Yamaha adalah variabel Harga karena memiliki tanda negatif (-).

\subsubsection{Standardized \\ Canonical Discriminant Function Coefficients}

Berguna untuk menganalisis responden yang diteliti akan termasuk kedalam kelompok mana yaitu kelompok pertama adalah pengguna sepeda motor merek Honda dan kelompok kedua adalah pengguna sepeda motor merek Yamaha.

Tabel 14. Hasil Uji Standardized Canonical Discriminant Function Coefficients

\begin{tabular}{|l|r|}
\hline \multirow{2}{*}{} & \multicolumn{2}{|c|}{ Function } \\
\cline { 2 - 2 } & \multicolumn{2}{|c|}{1} \\
\hline Produk $\left(\mathrm{X}_{1}\right)$ &, 486 \\
Harga $\left(\mathrm{X}_{2}\right)$ &,- 662 \\
Lokasi $\left(\mathrm{X}_{3}\right)$ &, 294 \\
Promosi $\left(\mathrm{X}_{4}\right)$ &, 252 \\
\hline
\end{tabular}

Sumber: Data Primer yang diolah, 2018.

Pada tabel Standardized Canonical Discriminant Function Coefficients:

$Z_{\mathrm{H}}=0,486 x_{1}+0,294 x_{3}+0,252 x_{4}$ $Z_{\mathrm{H}}=$ Model Diskriminan Honda 


$$
\begin{aligned}
& x_{1}=\text { Produk } \\
& x_{3}=\text { Lokasi } \\
& x_{4}=\text { Promosi }
\end{aligned}
$$

Jadi dapat disimpulkan dari model Honda jika produk meningkat satu satuan maka penjualan sepeda motor Honda meningkat sebesar 0,486. Jika lokasi meningkat satu satuan maka penjualan sepeda motor Honda meningkat sebesar 0,294 . Jika promosi meningkat satu satuan maka penjualan sepeda motor Honda meningkat sebesar 0,252.

\subsubsection{Classification Results}

Bertujuan untuk membuktikan keakuratan model diskriminan kita sangat akurat atau tepat untuk

\begin{tabular}{|c|c|c|c|c|c|}
\hline & & Sepeda & $\begin{array}{l}\text { Predict } \\
\text { Mem }\end{array}$ & $\begin{array}{l}\text { Group } \\
\text { rship }\end{array}$ & Total \\
\hline & & & Honda & Yamaha & \\
\hline & Count & Honda & 47 & 3 & 50 \\
\hline Oriain & Count & Yamaha & 1 & 49 & 50 \\
\hline Uigmal & $\%$ & Honda & 94,0 & 6,0 & 100,0 \\
\hline & $\%$ & Yamaha & 2,0 & 98,0 & 100,0 \\
\hline & Count & Honda & 47 & 3 & 50 \\
\hline Cross- & Count & Yamaha & 1 & 49 & 50 \\
\hline validated & o & Honda & 94,0 & 6,0 & 100,0 \\
\hline & $\%$ & Yamaha & 2,0 & 98,0 & 100,0 \\
\hline
\end{tabular}
dipertanggungjawabkan.

Tabel 15. Hasil Uji Classification Results

b. Cross validation is done only for those cases in the analysis. In cross validation, each case is classified by the functions derived from all cases other than that case.

c. $96.0 \%$ of cross-validated grouped cases correctly classified.

Sumber: Data Primer yang diolah, 2018.

Lihat data original pengguna sepeda motor pada count:

Honda - Honda: 47

Yamaha - Yamaha: 49

Total Responden : $100(50+50)$

Sehingga ketepatan model pada diskriminan: $(47+49) / 100=96 \%$. Model diskriminan layak digunakan untuk analisis diskriminan atau valid digunakan dalam penelitian ini karena diperoleh angka ketepatan yang tinggi yaitu $96 \%$.

\section{KESIMPULAN DAN SARAN}

5.1 Kesimpulan

Kesimpulan yang diperoleh dari penelitian ini yaitu:

1. Nilai skor pada uji perbedaan rata-rata lebih besar sepeda motor Honda dengan skor 211,58 poin sedangkan untuk skor sepeda motor Yamaha sebesar 202,42 poin. Hal ini menunjukkan terjadi perbedaan pilihan terhadap sepeda motor yang dibeli konsumen, dimana preferensi konsumen lebih besar terhadap pembelian sepeda motor honda matic. Hal ini terbukti di jalan raya lebih banyak sepeda motor honda beat dibandingkan yamaha mio.

2. Terdapat 4 perbedaan variabel antar grup dengan melihat nilai mean yang lebih besar antara dua grup pada tabel group statistics, untuk variabel dalam grup sepeda motor Honda yaitu, produk $(17,90)$, lokasi $(17,40)$ dan promosi (12,92) sedangkan untuk variabel dalam grup sepeda motor yamaha yaitu harga (13,38). Konsumen memilih untuk membeli sepeda motor merek honda karena melihat variabel produk, lokasi dan promosi dan konsumen memilih sepeda motor merek Yamaha karena variabel harga.

3. Ada perbedaan perilaku antara pengguna sepeda motor merek Honda maupun Yamaha karena memiliki nilai sig < 0,1 pada tabel Variables Entered/Removed.

4. Variabel terikat (Y) dapat dijelaskan oleh semua variabel bebas (produk, harga, lokasi dan promosi) sebesar $75,34 \%$ artinya semua variabel bebas berpengaruh positif terhadap variabel terikat (Y) keputusan pembelian.

5. Model diskriminan layak digunakan atau mampu melakukan klasifikasi 
atau prediksi responden dengan tepat untuk analisis diskriminan pada penelitian ini karena diperoleh angka ketepatan yang tinggi yaitu $96 \%$.

\subsection{Saran}

\subsubsection{Honda}

1. Perusahaan sepeda motor baik honda harus mempertahankan atau meningkatkan kualitas produk dengan melakukan inovasi model dan menambah fitur-fitur baru sesuai dengan keinginan dan kebutuhan konsumen. Meskipun harga yang ditawarkan oleh Honda cenderung lebih mahal dibandingkan merek lainnya, harga bukanlah faktor penentu utama konsumen untuk memutuskan pembelian sepeda motor Honda. Hasil penelitian membuktikan bahwa harga bukan satu-satunya penentu pilihan konsumen terhadap sepeda motor matic pada kelas yang sama. Walaupun harga yang ditawarkan oleh Honda cenderung lebih mahal dibandingkan merek lainnya, namun konsumen tetap memutuskan pembelian sepeda motor Honda.

2. Lokasi penjualan dan bengkel resmi sepeda motor Honda sudah banyak dan strategis, tetapi masih ada di daerahdaerah tertentu yang belum terjangkau oleh Honda. Sebagian lokasi penjualan dan bengkel resmi Honda mempunyai lahan parkir yang kurang luas dan kurang nyaman, menyebabkan konsumen malas untuk menunggu, sebaiknya perusahaan Honda juga memperluas lahan parkir sehingga konsumen menjadi nyaman untuk memilih sepeda motor Honda.

3. Perusahaan Honda juga harus mempertahankan bahkan meningkatkan promosi yang sudah dijalankan, harus terus mengevaluasi dan melakukan perbaikan-perbaikan strategi promosi dan memperhatikan alat promosi sehingga masyarakat akan terus mendapatkan informasi yang spesifik tentang produk Honda.

\subsubsection{Yamaha}

1. Perusahaan sepeda motor yamaha harus meningkatkan kualitas produk dengan melakukan inovasi model dan menambah fitur-fitur baru sesuai dengan keinginan dan kebutuhan konsumen. Menurut persepsi konsumen dalam hasil penelitian ini menyatakan bahwa pemakaian sepeda motor Yamaha kurang irit, oleh karena itu perusahaan harus memperhatikan pemakaian bahan bakar pada mesin sepeda motor Yamaha karena bahan bakar yang irit merupakan salah satu faktor yang mempengaruhi konsumen untuk membeli sepeda motor.

2. Perusahaan Yamaha seharusnya mengikuti pola penyebaran honda, dimana hampir setiap kecamatan bahkan desa terdapat dealer dan bengkel resmi honda. Perusahaan harus menambah lebih banyak lagi pembukaan bengkel resmi dan lokasi penjualan dengan cara mensurvei terlebih dahulu lokasi tersebut dan perusahaan juga dapat membuka subsub dealer di daerah terpencil.

3. Harga bukan satu-satunya penentu pilihan konsumen terhadap sepeda motor matic pada kelas yang sama. Perusahaan sebaiknya meningkatkan frekuensi iklan di media elektronik salah satunya di radio dan TV, promosi iklan yang dilakukan di media elektronik harus memperhatikan waktu tayangnya. Perusahaan sebaiknya memperluas lagi jangkauan promosi melalui media sosial dan lebih banyak lagi melakukan penyebaran brosur di tempat-tempat yang ramai pengunjung dan juga perusahaan dapat melakukan promosi dengan mensponsori acara- 
acara. Promosi juga dapat dilakukan dengan memberikan hadiah tambahan selain helm pada saat pembelian sepeda motor seperti kaos, payung, jam dinding dan sebagainya.

\section{DAFTAR PUSTAKA}

Alma, B. 2003. Manajemen Pemasaran dan Pemasaran Jasa. Edisi 2, CV Alfabeta. Bandung.

Dinawan. 2010. Kualitas Produk: Alat Strategi Yang Penting. Free Press: PT Raja Grafindo Persada. Jakarta.

Ghanimata, F. 2012. Analisis Pengaruh Harga, Kualitas Produk, dan Lokasi Terhadap Keputusan Pembelian (Studi pada Pembeli Produk Bandeng Juwana Elrina Semarang). Skripsi. Universitas Diponegoro Semarang.

Ghozali, I. 2005. Aplikasi Analisis Multivariate dengan Program SPSS. Edisi Kedua, Badan Penelitian Universitas Diponogoro. Semarang.

Kotler, P dan Keller, L.N. 2009. Manajemen Pemasaran. Edisi Ke 13, Jilid 1, Erlangga. Jakarta.

Kotler, P dan Keller, L.N. 2012. Marketing Management. Edisi 14, Global Edition. Pearson Prentice Hall.

Kotler, P. 2002. Manajemen Pemasaran. Edisi Millenium, Jilid 2, PT Prenhallindo. Jakarta.

Kotler, P. 2004. Marketing Management, The Millenium Edition. Englewood Cliffs, New Jersey. Precentice Hall.

Mischitelli, V. 2000. Your New Restaurant. Holbrook: Adams Media. Coorporation.

Rosvita, D. L. 2010. Analisis Pengaruh Kualitas Produk, Harga, Promosi dan Cuaca Terhadap Keputusan Pembelian Teh Siap Minum Dalam Kemasan Merek Teh Botol Sosro. Skripsi Fakultas Ekonomi Universitas Diponegoro Semarang.
Tjiptono, F. 2008. Strategi Pemasaran. Edisi Ketiga, ANDI. Yogyakarta. 